\section{Rucksacktouristen haben häufiger Geschlechtskrankheiten}

\section{Während Rucksackreisen sind flüchtige Sexualkontakte mit anderen Reisenden oder Einheimischen nicht selten. Ein australisches Autorenteam verglich Daten zum Risikoverhalten von Rucksacktouristen mit denen einer Kontrollgruppe gleichen Alters.}

er internationale Reiseverkehr spielt bei der Weiterverbreitung von sexuell übertragbaren Erkrankungen eine wichtige Rolle. Die Wahrscheinlichkeit für flüchtige sexuelle Kontakte während einer Reise in ein anderes Land liegt bei 5-50\%. Bei den Sexualpartnern handelt es sich entweder um andere Reisende oder um Einheimische. Studien haben gezeigt, dass die Rate der Kondombenutzung dabei zwischen $24-75 \%$ beträgt.

2006 besuchten 545.000 Rucksacktouristen Australien, wobei Sydney für die meisten (407.000) das Hauptreiseziel war. In der vorliegenden Untersuchung wurden demografische Daten, das Risikoverhalten und die Morbidität von 5.698 jungen Rucksackreisenden ausgewertet, die eine Ambulanz für übertragbare Sexualkrankheiten in Sydney zwischen 1998 und 2006 aufgesucht hatten. Als Vergleichskollektiv dienten australische Patienten gleichen Alters aus dem Krankengut der Klinik.

Die meisten der Rucksackreisenden stammten aus Großbritannien und waren im Durchschnitt 25 Jahre alt. Der Anteil der Frauen lag bei $52 \%$. Die Touristen gaben eine höhere Zahl von Sexualpartnern während des letzten Vierteljahres an als die Vergleichsgruppe (mindestens drei Sexualpartner bei $18 \%$ versus $12 \%$, $\mathrm{p}<0,001)$. Sie tranken auch häufiger kritische Mengen Alkohol (22\% versus 9\%, $\mathrm{p}<0,001)$. Die Rate der konstanten Benutzung von Kondomen war bei Rucksackreisenden in den letzten drei Monaten wie auch bei der Kontrollpopulation vergleichbar niedrig (22\% versus 19\%). Die Touristen hatten häufiger eine Chlamydien-Infektion ( $7 \%$ versus $5 \%, p<0,001$ ) als die Kontrollpopulation und gaben auch eine höhere Rate von vorangegangenen sexuell übertragbaren Erkrankungen an ( $15 \%$ versus $10 \%, \mathrm{p}<0,001)$.
Kommentar: Die Studienautoren analysierten am Beispiel Sydney das Sexualverhalten von Rucksacktouristen. Auch Europa wird von einer hohen Zahl von Rucksackreisenden bereist, wobei es hier ebenfalls zu flüchtigen Sexualkontakten kommen dürfte. Eines der Hauptreiseziele ist jedes Jahr das Münchner Oktoberfest. Somit dürften sich die Kernaussagen über das Verhalten von Rucksackreisenden auch auf Europa übertragen lassen. In der Sprechstunde ist eine gezielte Suche nach sexuell übertragbaren Erkrankungen beziehungsweise eine anamnestische Befragung zu Sexualkontakten durchaus sinnvoll, wenn die Patienten Rucksacktouristen sind oder von einer entsprechenden Reise zurückgekehrt sind.

Prof. Dr. Tino F. Schwarz

McNulty AM et al. The behaviour and sexual health of young international travellers (backpackers) in Australia. Sex Transm Infect 2010; 86: 247-50

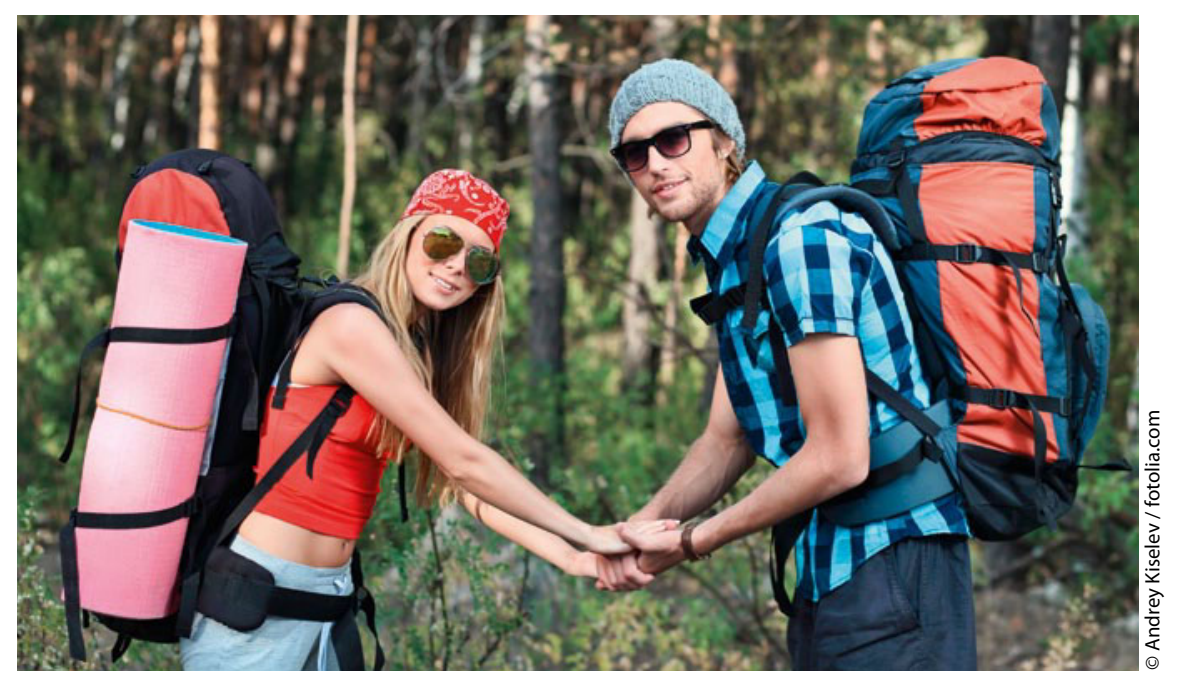

Sexualkontakte im Urlaub sind nicht selten - teilweise mit unerwünschten Folgen. 